\title{
Improved Prediction of Phosphorus Dynamics in Biotechnological Processes by Considering Precipitation and Polyphosphate Formation: A Case Study on Antibiotic Production with Streptomyces coelicolor
}

Burger, Patrick; Flores-Alsina, Xavier; Arellano-Garcia, Harvey; Gernaey, Krist V.

Published in:

Industrial and Engineering Chemistry Research

Link to article, DOI:

10.1021/acs.iecr.7b05249

Publication date:

2018

Document Version

Peer reviewed version

Link back to DTU Orbit

Citation (APA):

Burger, P., Flores-Alsina, X., Arellano-Garcia, H., \& Gernaey, K. V. (2018). Improved Prediction of Phosphorus Dynamics in Biotechnological Processes by Considering Precipitation and Polyphosphate Formation: A Case Study on Antibiotic Production with Streptomyces coelicolor. Industrial and Engineering Chemistry Research, 57(30), 9740-9749. https://doi.org/10.1021/acs.iecr.7b05249

\section{General rights}

Copyright and moral rights for the publications made accessible in the public portal are retained by the authors and/or other copyright owners and it is a condition of accessing publications that users recognise and abide by the legal requirements associated with these rights.

- Users may download and print one copy of any publication from the public portal for the purpose of private study or research.

- You may not further distribute the material or use it for any profit-making activity or commercial gain

- You may freely distribute the URL identifying the publication in the public portal 


\section{Bioengineering}

Subscriber access provided by DTU Library

\section{Improved Prediction of Phosphorus Dynamics in Biotechnological} Processes by Considering Precipitation and Polyphosphate Formation: A Case Study on Antibiotic Production with Streptomyces coelicolor

Patrick Bürger, Xavier Flores Alsina, Harvey Arellano-Garcia, and Krist V. Gernaey

Ind. Eng. Chem. Res., Just Accepted Manuscript • DOI: 10.1021/acs.iecr.7b05249 • Publication Date (Web): 17 Apr 2018

Downloaded from http://pubs.acs.org on April 22, 2018

\section{Just Accepted}

"Just Accepted" manuscripts have been peer-reviewed and accepted for publication. They are posted online prior to technical editing, formatting for publication and author proofing. The American Chemical Society provides "Just Accepted" as a service to the research community to expedite the dissemination of scientific material as soon as possible after acceptance. "Just Accepted" manuscripts appear in full in PDF format accompanied by an HTML abstract. "Just Accepted" manuscripts have been fully peer reviewed, but should not be considered the official version of record. They are citable by the Digital Object Identifier (DOI®). "Just Accepted" is an optional service offered to authors. Therefore, the "Just Accepted" Web site may not include all articles that will be published in the journal. After a manuscript is technically edited and formatted, it will be removed from the "Just Accepted" Web site and published as an ASAP article. Note that technical editing may introduce minor changes to the manuscript text and/or graphics which could affect content, and all legal disclaimers and ethical guidelines that apply to the journal pertain. ACS cannot be held responsible for errors or consequences arising from the use of information contained in these "Just Accepted" manuscripts. 


\title{
Improved Prediction of Phosphorus Dynamics in
}

\author{
Biotechnological Processes by Considering
}

\section{Precipitation and Polyphosphate Formation: A Case}

\section{Study on Antibiotic Production with Streptomyces}

\section{coelicolor}

Patrick Bürger $^{a *}$, Xavier Flores-Alsina ${ }^{b}$, Harvey Arellano-Garcia ${ }^{c}$, Krist V. Gernaey ${ }^{b}$

${ }^{\mathrm{a}}$ Department of Particle Technology, Brandenburg University of Technology Cottbus-

Senftenberg, Building LG 4/3, Burger Chaussee 2, D-03046 Cottbus, Germany

${ }^{b}$ Process and Systems Engineering Center (PROSYS), Department of Chemical and Biochemical

Engineering, Technical University of Denmark, Building 229, 2800 Kgs. Lyngby, Denmark

${ }^{\mathrm{c}}$ Department of Chemical and Process Engineering, Faculty of Engineering and Physical

Sciences, University of Surrey, Guildford GU2 7HX, United Kingdom

telephone: +49 355691209 fax: +49355691121 e-mail: patrick.buerger@b-tu.de

KEYWORDS Streptomyces coelicolor, calcium phosphate precipitation, physico-chemistry, speciation model, polyphosphate, phosphorus storage, antibiotic production 


\begin{abstract}
The multiplicity of physico-chemical and biological processes, where phosphorus is involved, makes their accurate prediction using current mathematical models in biotechnology quite a challenge. In this work, an antibiotic production model of Streptomyces coelicolor is chosen as a representative case study in which major difficulties arise in explaining the measured phosphate dynamics among some minor additional issues. Thus, the utilization of an advanced speciation model and a multiple mineral precipitation framework is proposed to improve phosphorus predictions. Furthermore, a kinetic approach describing intracellular polyphosphate accumulation and consumption has been developed and implemented. A heuristic re-estimation of selected parameters is carried out to improve overall model performance. The improved process model predicts phosphate dynamics (Root Mean Squared Error $\leq 52 \mathrm{~h}$ : $-90 \%$, Relative Average Deviation $\leq 52 \mathrm{~h}:-96 \%$ ) very accurately in comparison to the original implementation, where biomass growth/decay was the only phosphorus source-sink. In addition, parameter re-estimation achieved an improved description of the available measurements for biomass, total ammonia, dissolved oxygen and actinorhodin concentrations.
\end{abstract}

This work contributes to the existing process knowledge of biotechnological systems in general and especially to antibiotic production with $S$. coelicolor, while emphasizing the (unavoidable) need of considering both physico-chemical and biological processes to accurately describe phosphorus dynamics. 


\section{Introduction}

Modelling biotechnological processes, for instance pharmaceutical production or wastewater treatment plants, often faces the difficult challenge of describing the phosphorus dynamics accurately while e.g. phosphate influences the biological process considerably (important nutrient, buffer capacity). Addressing this issue requires a major, but unavoidable, degree of complexity due to the strong non-ideal behavior caused by the phosphate trivalence. This includes, extensive consideration of activities instead of molar concentrations, continuous ionic strength tracking and the consideration of ion complexation and precipitation processes ${ }^{1}$. While phosphate-related precipitation would reduce the amount of available phosphate, it may also reduce the availability of essential ions for the microorganisms by precipitate formation. Additionally, phosphate accumulation as intra-cellular polyphosphate (polyP) may occur when certain microorganisms are subjected to high available phosphate concentrations in the fermentation media ${ }^{2,3}$.

This work uses a bacterial growth model of Streptomyces coelicolor as case study ${ }^{4}$. The first simple model of S. coelicolor was published in 1999 by Elibol and Mavituna ${ }^{5}$. In 2003 the genome of the strain S. coelicolor M145 was fully sequenced causing its popularity among researchers who investigated the metabolism in several studies ${ }^{6,7,8,9,10}$. S. coelicolor produces two antibiotics (actinrhodin and undecylprodigiosin) after the consumption of the phosphorus source (phosphate) due to the activation of a metabolic switch ${ }^{8}$. Therefore, an accurate phosphorus prediction will end up affecting overall model performance due to its accounted impact using inhibition/half saturation terms. The original model was selected due to its inability in describing the phosphate dynamics and its potential value for antibiotics production. Health care and the production of antibiotics relies heavily on the wide range of antibiotics produced by bacteria of the genus Streptomyces ${ }^{9}$. 
This study emphasizes the need to implement a hybrid approach to describe phosphorus dynamics more effectively by considering the phosphorus-related biological accumulation/release of $S$. coelicolor $^{11}$ and physico-chemical processes (speciation, precipitation) at the same time.

\section{Modeling aspects}

\subsection{Description of the original model and identification of prediction deficiencies}

The antibiotic production model selected for this case study is composed of three parts covering microbiological aspects (biological model), chemical speciation (weak acid/base approach) and gas-liquid phase mass transfer (two film model) (see Sin et al. for detailed information ${ }^{4}$ ). The Ordinary Differential Equations (ODE) system includes 13 process rates which are used for the calculation of 21 continuous state variables. Most concentrations are described accurately by the original implementation (e.g. biomass, glucose, antibiotic products, off-gas $\mathrm{CO}_{2}$, base addition).

However, the model under-predicts the total ammonia concentration from the exponential phase of the batch fermentation onwards (see Figure $3,2^{\text {nd }}$ row left, black dashed line). Secondly, the model over-predicts dissolved oxygen during the exponential phase (see Figure $3,3^{\text {rd }}$ row left, black dashed line). The largest drawback of the original process model is the description of the total phosphate concentration, which does not fit the experimental data at any time of the fermentation (see Figure 2, black dashed line). Whereas the predictions for the total ammonia concentration and dissolved oxygen may be improved significantly by a re-adjustment of two estimated parameters (biomass composition and $\mathrm{k}_{\mathrm{L}} \mathrm{a}$, respectively), the insufficient description of the phosphate dynamics suggests that the model currently does not incorporate sufficient process knowledge to predict the total phosphate concentration. Biomass growth is the only phosphorus sink in the original model and the composition of biomass was estimated $\left(\mathrm{CH}_{1.8} \mathrm{O}_{0.5} \mathrm{~N}_{0.2111} \mathrm{P}_{0.0094}\right)$. 
Therefore, the model needs to be updated with improved process kinetics/stoichiometry and thus enabling an accurate description of phosphate dynamics which is the key objective of this work. An accurate description of phosphate is necessary to estimate the biological parameters accurately, since the experimental data was obtained under phosphate-limited experimental conditions. Moreover, process models should be able to describe accurately the most relevant concentrations (substrates, biomass and products) whenever model-based optimization is intended in production processes.

\subsection{Model enhancement strategies}

An accurate description of phosphorus dynamics in biotechnological processes requires the consideration of physical processes and phosphorus-related biochemical processes, even if this leads to a structured model due to the modelling of intracellular components. Following this train of thought, the impact of precipitation and polyphosphate formation on the phosphate dynamics is investigated in this case study. Modelling precipitates requires a rigorous and extensive calculation of the species distribution in the fermentation media ${ }^{12}$. Therefore, the simplified weak acid base approach used in the original model is replaced here with an advanced speciation model by FloresAlsina et al. ${ }^{13}$ leading to the baseline model (see section 3.2). Extensive use of activities instead of molar concentrations and continuous ionic strength tracking enables the proposed speciation model to deal with the strong non-ideal behavior typical for phosphorus compounds. Based on this model enhancement, a multiple mineral precipitation framework by Kazadi Mbamba et al. ${ }^{14}$ is implemented to investigate phosphate-associated precipitation phenomena in the fermentation media (see section 3.3). Furthermore, simplified polyphosphate kinetics are developed and implemented to investigate the potential formation of intracellular polyphosphate (polyP) and the resulting impact on the description of the phosphate dynamics (see section 3.4). Each modification 
or model extension was introduced gradually and tested thoroughly with different parameter setups to ensure model integrity and to assess the behavior of each upgrade and its respective impact on the process model. Thus, the number of continuous states of the modified and enhanced model increases to 37 . This is, mainly due to the accurate description of inorganic compounds (see Table 1) by the speciation model, which requires 12 states.

\section{Material and Methods}

\subsection{Data set and original S. coelicolor process model}

In this work, the experimental data from batch fermentations reported by Sin and co-workers ${ }^{4}$ is used. For further information about materials and methods regarding the experimental work and detailed information about their antibiotic production model, the reader is kindly referred to the work of Sin et al. ${ }^{4}$. A summary of process conditions for the model validation is given by Ödman ${ }^{15}$.

\subsection{Establishing communication between the advanced speciation model and the original process} model (Development of the baseline model)

The replacement of the original simplified weak acid/base approach with the speciation model provided by Flores-Alsina et al. ${ }^{13}$ requires a translation of the $S$. coelicolor process model from a MATLAB-script into an S-function for its use in the Simulink environment. It is important to emphasize that there are other potential options in Matlab to handle this type of system such as using the MASS function in the ode15s solver. In our case, the S-function version of the speciation model provided a fast and robust calculation of the equilibrium reactions described as a system of algebraic equations (AE) and solved as DAE since it is linked to the general ODE system (here: $S$. coelicolor process model, describing the biological processes and the gas-liquid phase mass transfer). In addition, the approach was compatible with other models developed by the group ${ }^{16}$. 
Prior to the coupling with the speciation model, the results of the translated process model were compared with the original model to verify an accurate translation.

Coupling requires establishing the interactions between both $\mathrm{S}$-functions which involves the creation of additional continuous states in the process model to provide the total concentrations (e.g. $\mathrm{NH}_{\mathrm{X}}$ ) for the speciation model at every time step. The baseline model consists of the process model and the advanced speciation model which are solved simultaneously in Simulink. A scheme of the interactions between both parts in the baseline model is shown in Figure 1.

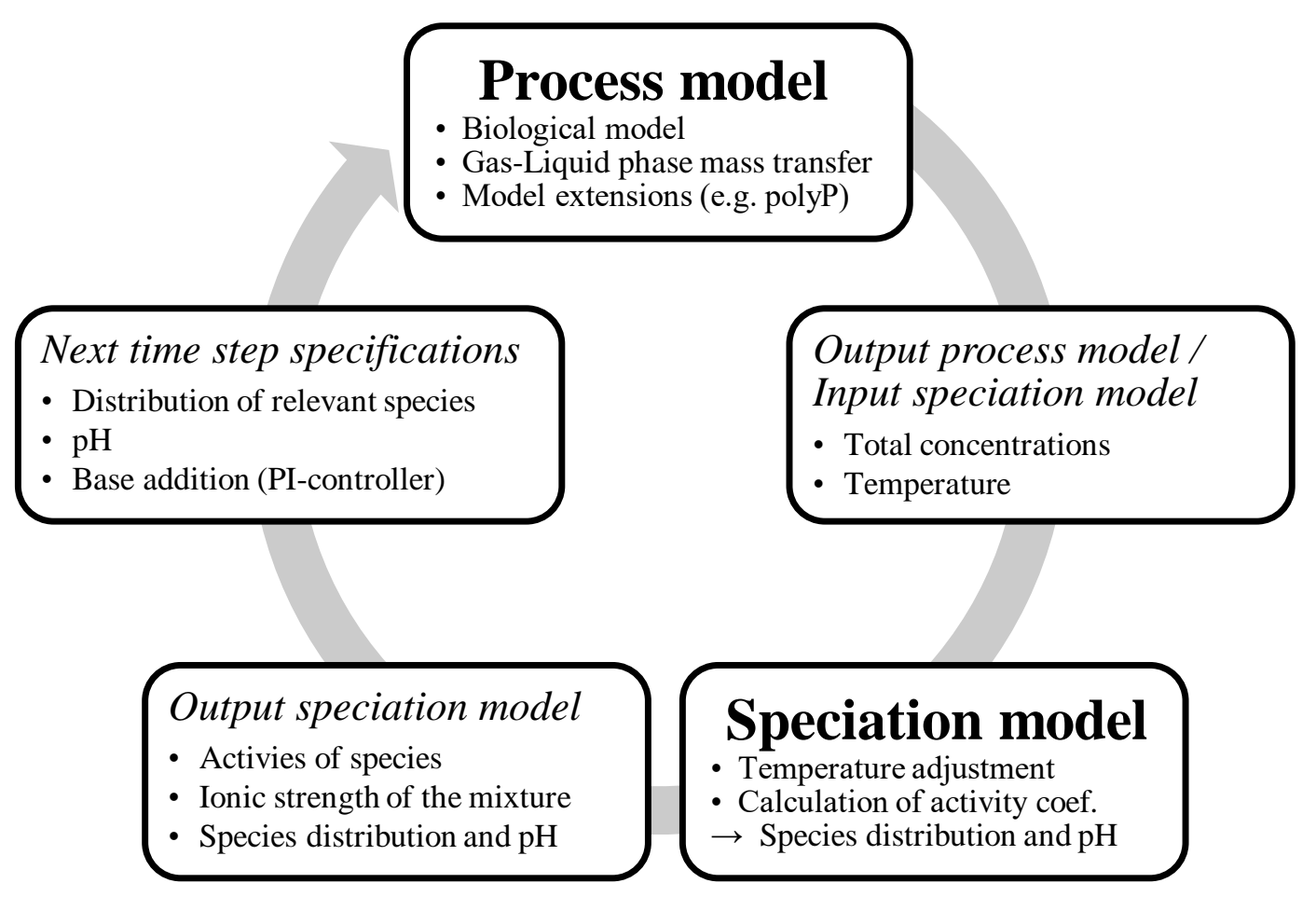

Figure 1. Schematic description of the interactions in the baseline model between process model and advanced speciation model at every time step during the simulation (both models are solved simultaneously).

Based on this information, the speciation model calculates the ionic strength, the activity coefficients, and the species distribution. The base addition required to keep the $\mathrm{pH}$ at operating conditions is determined by an additional PI-controller (used for $\mathrm{pH}$ control in the experiment as 
well), which acts based upon the information at every time step provided by the speciation model and prevents a shifting of species distribution. The species distribution (e.g. $\mathrm{NH}_{4}{ }^{+}$and $\mathrm{NH}_{3}$ ) and the base addition are forwarded to the process model for the calculations in the next time step. Similar approaches regarding overall model structure and model communication have been used in several studies ${ }^{13,17,18}$. The composition of the fermentation media and the resulting initial total concentrations required to operate the speciation model are summarized in Table 1.

Table 1. Composition of the fermentation media used by Sin et al., $2008^{4}$ and resulting initial total concentrations considered in the speciation model.

\begin{tabular}{|c|c|c|c|c|c|c|c|c|c|c|}
\hline \multicolumn{11}{|c|}{ Concentrations in the fermentation media (from nutrient solution, based on Sin et al. ${ }^{4}$ ) } \\
\hline Component & $\mathrm{Na}_{2} \mathrm{SO}_{4}$ & \multicolumn{2}{|c|}{ NaCitrate } & $\mathrm{KCl}$ & $\mathrm{MgCl}_{2}$ & $\mathrm{CaCl}_{2}$ & \multicolumn{2}{|c|}{$\mathrm{NaH}_{2} \mathrm{PO}_{4}$} & $\mathrm{NH}_{4} \mathrm{Cl}$ & Glucose \\
\hline Conc. $[\mathrm{mmol} / \mathrm{L}]$ & 2 & \multicolumn{2}{|r|}{2} & 10 & 2 & 1.25 & 3 & \multicolumn{2}{|c|}{100} & 222.2 \\
\hline \multicolumn{11}{|c|}{ Concentrations in the fermentation media (from trace metal solution, based on Sin et al. ${ }^{4}$ ) } \\
\hline Component & $\mathrm{FeCl}_{3}$ & \multicolumn{2}{|r|}{$\mathrm{CuCl}_{2}$} & $\mathrm{ZnCl}_{3}$ & \multicolumn{2}{|c|}{$\mathrm{MnCl}_{2}$} & $\mathrm{Na}_{2} \mathrm{MoO}_{4}$ & \multicolumn{2}{|c|}{$\mathrm{CoCl}_{2}$} & $\mathrm{H}_{3} \mathrm{BO}_{4}$ \\
\hline Conc. $[\mathrm{mmol} / \mathrm{L}]$ & 0.3 & \multicolumn{2}{|r|}{0.15} & 0.75 & \multicolumn{2}{|c|}{0.15} & 0.0003 & \multicolumn{2}{|c|}{0.3} & 0.15 \\
\hline \multicolumn{11}{|c|}{ Resulting initial total concentrations for the speciation model based on fermentation media ingredients } \\
\hline Component & $\mathrm{H}$ & $\mathrm{Na}$ & $\mathrm{K}$ & $\mathrm{NHX}$ & $\mathrm{Cl}$ & $\mathrm{Ca}$ & $\mathrm{Mg}$ & $\mathrm{CO}_{3}$ & $\mathrm{SO}$ & $\mathrm{PO}_{4}$ \\
\hline Conc. $[\mathrm{mmol} / \mathrm{L}]$ & 7.1 & 9.17 & 10 & 101.78 & 116.5 & 1.25 & 2.0 & 1.0494 & 2.0 & 3.075 \\
\hline
\end{tabular}

Since the speciation model requires an initial value for the ionic strength and an initial distribution, the geochemical software MINTEQ was used for the calculation based upon the ingredients of the defined mineral fermentation media used in the experimental work.

\subsection{Implementation of the multiple mineral precipitation framework into the baseline model}

The prediction of precipitates in the fermentation media is realized by selective implementation of a validated (lab- and full-scale) multiple mineral precipitation framework developed by Kazadi Mbamba et al. ${ }^{14}$. A group of 13 possible precipitates was investigated in a saturation index (SI) profile screening based on the specified fermentation media composition, which revealed only four oversaturated minerals: dolomite $\left(\mathrm{CaMg}\left(\mathrm{CO}_{3}\right)_{2}\right)$, newberyite $\left(\mathrm{MgHPO}_{4} \cdot 3 \mathrm{H}_{2} \mathrm{O}\right)$, amorphous 
calcium phosphate $\left(\mathrm{ACP}, \mathrm{Ca}_{3}\left(\mathrm{PO}_{4}\right)_{2}\right)$, and calcium hydrogen phosphate $\left(\mathrm{CaHPO}_{4}\right)$. Therefore, the precipitation kinetics for these four minerals are implemented into the process model (see Figure 1). Exemplarily, Equation 1 shows the saturation index calculations for the precipitate ACP.

$$
S I_{A C P\left(\mathrm{Ca}_{3} \mathrm{P}_{2} \mathrm{O}_{8}\right)}=\log _{10}\left(\frac{\left(a_{C a^{2+}}\right)^{3} *\left(a_{\mathrm{PO}_{4}{ }^{3-}}\right)^{2}}{K_{\text {precip }, A C P}}\right)
$$

The precipitate formation rate of ACP is shown in Equation 2.

$$
r_{A C P-\text { formation }}=k_{A C P} * C_{A C P} *\left(\left(10^{S I_{A C P}}\right)^{1 / 5}-1\right)^{n_{A C P}}
$$

To reduce the computational load and prevent erroneous calculations, an if-else structure sets the formation rate of a precipitate to zero whenever the respective saturation index is below zero by using Boolean variables. The precipitation kinetics need to be provided with initial precipitate concentrations, since the used kinetics do not account for nucleation phenomena.

\subsection{Implementation of the polyphosphate kinetics into the baseline model}

The implementation of polyphosphate kinetics is the last major modification/extension of the process model (see Figure 1). This allows to investigate the possibility of intracellular phosphate storage in Streptomyces coelicolor and converts the model into a structured biological model, i.e. a model where intracellular components are considered.

While the influence of phosphate and polyP on the metabolism of S. coelicolor is a common field of research from a microbiological point of view, the kinetics of polyP formation, degradation and subsequent consumption have not yet been described and incorporated into process models. The model-based impact assessment of polyP formation on the extracellular phosphate concentration in the fermentation media does not require a mechanistical kinetic approach for polyP formation 
(structure and composition of the polymer) as polyP is stored intracellularly. Therefore, a simplified kinetic Monod-type approach was developed (Eq. 3) which considers lag time, biomass concentration $\left(\mathrm{C}_{\mathrm{X}}\right)$, total phosphorus concentration $\left(\mathrm{C}_{\text {total-PO4 }}\right)$, and dissolved oxygen $\left(\mathrm{C}_{\mathrm{dO} 2}\right)$.

Modelling polyphosphate as internal phosphate $\left(\mathrm{PO}_{4}\right)$ instead of a polymer results in a simple stoichiometry and does not require additional polymerization and depolymerization kinetics for the prediction of phosphate in the fermentation media. The use of dissolved oxygen (term 3 ) in the kinetic expression accounts for reduced polyP formation if periods of limited oxygen supply occur. The dependency of polyP formation on the respiratory activity and therefore on available oxygen content in the fermentation media is emphasized by Pavlov et al. (2010) ${ }^{19}$ and other research $\operatorname{groups}^{20,21,22,23}$.

$$
r_{\text {polyP }}=k_{\text {polyP }} * \frac{1}{1+e^{t_{\text {lag }}-t}} * \frac{C_{d O_{2}}}{K_{d O_{2}}+C_{d O_{2}}} * \frac{C_{\text {total }-\mathrm{PO}_{4}}}{K_{\text {total }-\mathrm{PO}_{4}}+C_{\text {total-PO}}} * C_{X}
$$

The polyphosphate kinetics are completed by the description of the polyP degradation and subsequent consumption, which is modelled as polyP-based growth based on the assumption that this occurs when phosphate is depleted in the fermentation media. Therefore, a modified version of the used Monod-type growth kinetic (Eq. 4) was developed (see Eq. 5) by replacing the dihydrogen phosphate term with a polyP term (term 6) and adding an inhibition term (term 7), which prevents polyP-based growth before the phosphate in the media is depleted. Thus, both growth kinetics are present in the process model.

$$
\begin{aligned}
r_{X}=\mu_{\max } * & \frac{1}{1+e^{t_{l a g}-t}} * \frac{C_{G l c}}{K_{G l c}+C_{G l c}} * \frac{C_{d O_{2}}}{K_{d O_{2}}+C_{d O_{2}}} * \frac{C_{d N H_{3}}}{K_{d N H_{3}}+C_{d N H_{3}}} \\
& * \frac{C_{\mathrm{H}_{2} \mathrm{PO}_{4}}}{K_{\mathrm{H}_{2} \mathrm{PO}_{4}}+C_{\mathrm{H}_{2} \mathrm{PO}_{4}}} * C_{X}
\end{aligned}
$$




$$
\begin{gathered}
r_{X, \text { polyP }}=\mu_{\text {max }, \text { polyP }} * \frac{1}{1+e^{t_{\text {lag }}-t}} * \frac{C_{G l c}}{K_{G l c}+C_{G l c}} * \frac{C_{d O_{2}}}{K_{d O_{2}}+C_{d O_{2}}} * \frac{C_{d N H_{3}}}{K_{d N H_{3}}+C_{d N H_{3}}} \\
* \frac{C_{\text {polyP }}}{K_{\text {polyP }}+C_{\text {polyP }}} * \frac{K_{\text {Inihib-PO}}}{K_{\text {Inihib }-\mathrm{PO}_{4}}+C_{\mathrm{H}_{2} \mathrm{PO}_{4}}} * C_{X}
\end{gathered}
$$

Finally, the inhibition terms used in the production rates of the antibiotic products are adapted for accurate prediction since external and intracellular phosphate needs to be considered for the metabolic switch towards the production of antibiotics ${ }^{24,25}$. Similar structures describing polyP formation can be found in the Activated Sludge Model No. 2d (ASM2d), which is popular in wastewater research ${ }^{26}$.

\subsection{Parameter re-estimation and model evaluation}

The last step in model development is a heuristic re-estimation of selected parameters which ensures the best use of the implemented process kinetics leading to an accurate prediction. This approach is based on changing the least possible number of parameters. Besides the newly introduced parameters necessary for the additional kinetics, 11 parameters of the original model are investigated and adapted. Most of these parameters are modified in acknowledgement of the additional kinetics describing the phosphate dynamics. However, the nitrogen content in the biomass composition $\left(\mathrm{i}_{\mathrm{NX}}\right)$ and the volumetric mass transfer coefficient for oxygen $\left(\mathrm{k}_{\mathrm{L}} \mathrm{a}\right)$ are readjusted to improve the description of total ammonia and dissolved oxygen, respectively. As for total ammonia, the original model used a generic biomass composition, which may not be entirely accurate for S. coelicolor. However, the ammonia dynamics are not the scope of this study.

Model performance of the original and the enhanced model is evaluated qualitatively by visual inspection supported by two quantitative methods: the root mean square error (RMSE) and the 
relative average deviation (RAD). The RMSE identifies large deviations (i.e. at high concentrations), while the RAD is more suitable for the evaluation at low concentrations.

\section{Results and Discussion}

\subsection{Model comparison}

In this section, the results of the original model (M0) by Sin et al. ${ }^{4}$ are compared with the latest version of our enhanced model (M1). During the examination of the experimental data set obtained from batch fermentations by $\mathrm{Sin}$ et $\mathrm{al}^{4}{ }^{4}$, it came to our attention that the last data point of four aqueous process variables (biomass, total ammonia, total phosphate, actinorhodin) was significantly under-predicted. We suspect that this may have been caused by a dilution error of $20 \%$ during sample handling. The corrected data point is indicated in the diagrams (open square).

\subsubsection{Phosphate dynamics}

Based on the investigations conducted in this study, M1 combines precipitation and polyphosphate kinetics to achieve the very accurate prediction of the phosphate dynamics shown in Figure 2 (black solid line). It becomes clear that the formation of ACP (black dotted line) occurs in the lag phase while polyP formation (grey dot dash line) describes the phosphate dynamics in the exponential phase. The occurrence of precipitation coinciding with the lag phase of this fermentation may be explained by the phosphate-limited experimental approach, causing moderate oversaturation according to the saturation index and therefore a slow precipitation process.

The ACP formation (none of the other precipitates was formed) may also explain the measured non-zero values from $52 \mathrm{~h}$ onwards since interference of the precipitate in the spectrophotometric measurements of total phosphate could be an issue (malachite green complex). This theory is 
supported by the metabolic switch of S. coelicolor induced by the depletion of available phosphate causing the production of antibiotics ${ }^{9}$.

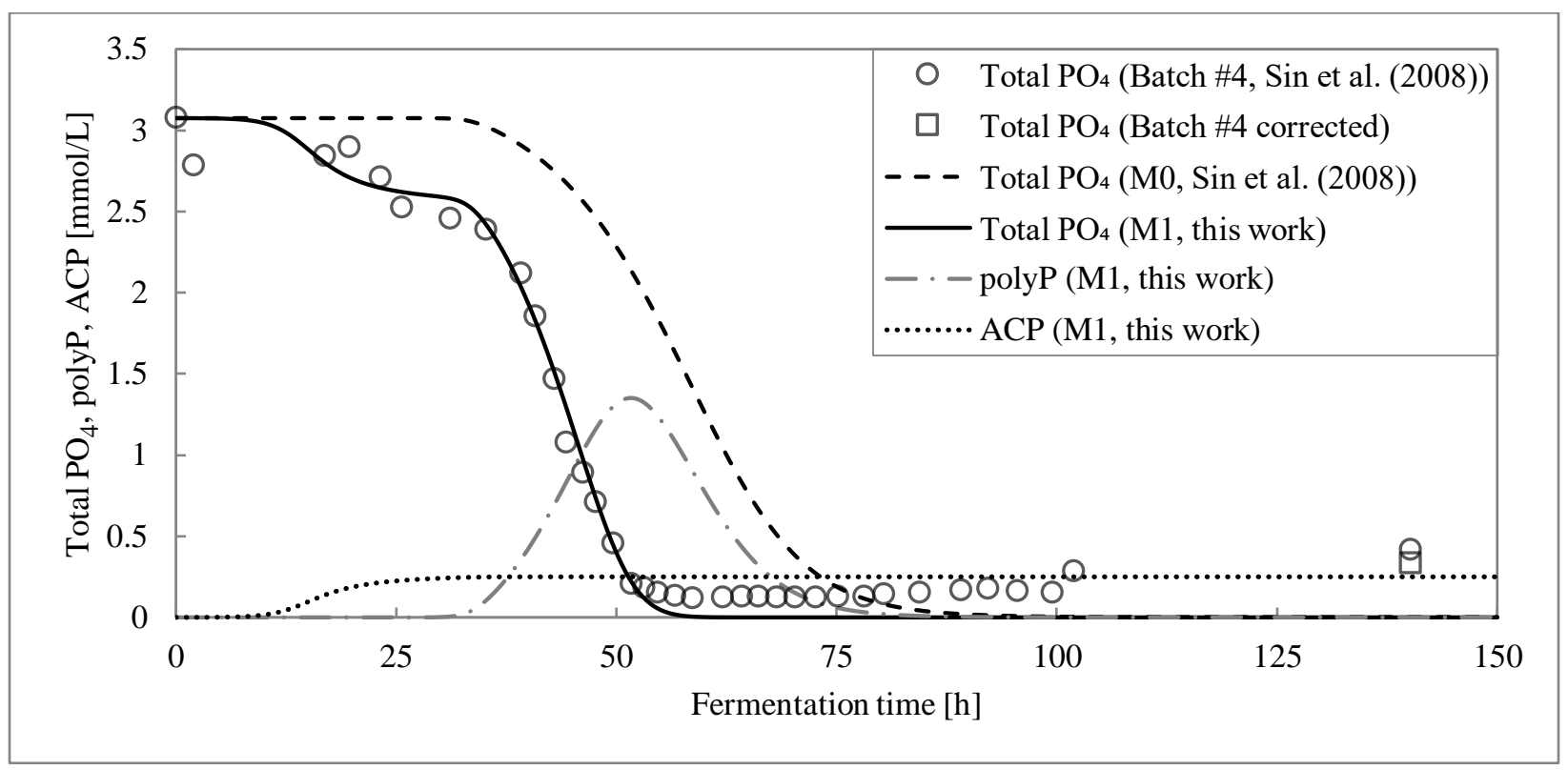

Figure 2. Comparison of the total phosphate predictions by the original model (M0) by Sin et al., $2008^{4}$ (black dashed line) and the enhanced model (M1) proposed in this study (black solid line). ACP (black dotted line) and polyphosphate (grey dash dot line) are predicted by the enhanced model. The experimental data points are based on batch \#4 carried out by Sin et al., $2008^{4}$ (open circles) and corrected data points due to a suspected dilution error are indicated as open squares.

Based on the stoichiometric formula of ACP $\left(\mathrm{Ca}_{3}\left(\mathrm{PO}_{4}\right)_{2}\right)$ and the final concentration of 0.25 $\mathrm{mmol} / \mathrm{L}$, the amount of phosphate not available for growth sums up to $0.5 \mathrm{mmol} / \mathrm{L}$ corresponding to $16.3 \%$ of the total initial phosphate concentration. This is especially relevant because the experimental setup by Sin et al. ${ }^{4}$ was designed as a phosphate-limited approach. Therefore, an unwanted and unexpected decrease in the phosphate concentration might lead to wrong assumptions or faulty estimations of parameters from conducted measurements. The evaluation of the model performance for phosphate predictions (M1) until $52 \mathrm{~h}$ fermentation time reveals an impressive reduction in $\mathrm{RMSE}_{\leq 52 \mathrm{~h}}$ by $90 \%$ and in $\mathrm{RAD}_{\leq 52 \mathrm{~h}}$ by $96 \%$ compared to the original model (M0). 


\subsubsection{Overall model performance}

While presenting a comprehensive approach to describe phosphorus dynamics in biotechnological processes is the main goal of this study, the improvement of predictions for the other variables captured by this antibiotic model is perceived as an additional important task leading to a condensed description of process knowledge in the enhanced model (M1).

The description of the total ammonia concentration is improved significantly (RMSE: - $69 \%$, RAD: $-76 \%$ ) by adapting the nitrogen content in the biomass composition, which is the only nitrogen sink in the process model (see Figure $3,2^{\text {nd }}$ row left, black solid line). The phosphorus content in the biomass composition is adapted slightly to acknowledge the reduction of available phosphate by ACP formation ensuring an accurate prediction of biomass (RMSE: - $40 \%$, RAD: - $27 \%$ ) in the phosphate-limited experimental setup (see Figure $3,1^{\text {st }}$ row right, black solid line). The improved prediction of the biomass concentration during the stationary phase and the decay phase is achieved by a small adaptation of the rate constants of the maintenance and decay kinetics (see Figure 3, $1^{\text {st }}$ row right, black solid line). Due to the improved prediction of biomass by the enhanced model in the exponential phase, the glucose prediction appears to be slightly less accurate in this phase than in the original model. However, the glucose concentration is predicted with reasonable accuracy in both cases. An improved prediction for the antibiotic products actinorhodin (ACT, see Figure 3, 2n row right, black solid line) and undecylprodigiosin (RED, not shown) is achieved by the implemented polyP kinetics and by adapting the respective rate constants and inhibition constants. While the prediction of ACT was improved significantly (RMSE: - $60 \%$, RAD: - $70 \%$ ) from 60h fermentation time onwards, measurement uncertainties visible at $90 \mathrm{~h}$ fermentation time are clearly an issue for this variable. 

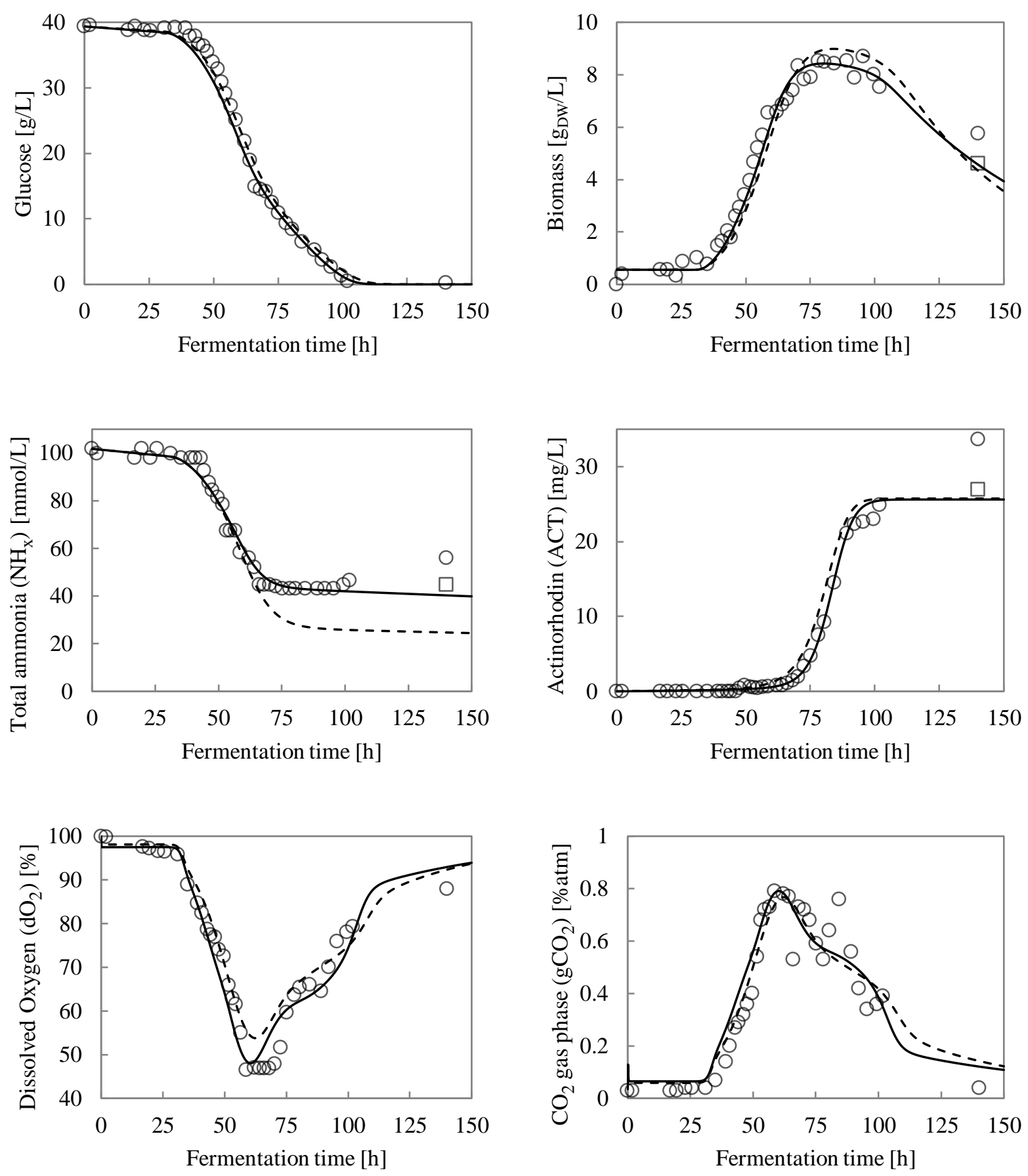

Figure 3. Comparison of the predictions by the original model (M0) by Sin et al., $2008^{4}$ (black dashed line) and the enhanced model (M1) proposed in this study (black solid line) for glucose, biomass, total ammonia, actinorhodin, dissolved oxygen and gaseous $\mathrm{CO}_{2}$. The experimental data points are based on batch \#4 carried out by Sin et al., $2008^{4}$ (open circles) and corrected data points due to a suspected dilution error are indicated as open squares. 
The uncertainties in the experimental data for RED prevented a significant improvement of the prediction for this variable (RMSE: $+1 \%$, RAD: $-30 \%$ ) based on the available data set. The reduction of the $\mathrm{k}_{\mathrm{L}} \mathrm{a}$-value compared to the original model improves the fit of the dissolved oxygen concentration (see Figure 3, $3^{\text {rd }}$ row left, black solid line), which is supported by the evaluation criteria (RMSE: - $11 \%$, RAD: - $13 \%$ ). However, visual inspection reveals a persisting model-data discrepancy between 62 and 75 hours fermentation time, where the fermentation undergoes a transition from the exponential phase into the stationary phase. Therefore, a higher demand of oxygen during the growth on polyP than on dihydrogen phosphate would not explain the observed discrepancy. The idea of an increased oxygen demand for maintenance purposes was proved wrong because the glucose concentration was no longer predicted accurately when this feature was incorporated in the model. All attempts to describe the $\mathrm{dO}_{2}$ in this period by applying changes to the biological model did not show any evidence that the problem might be in the kinetics. It is believed that mass transfer limitations close to the sampling probe could be a possible explanation. Those may be caused by the structure (hyphae) of the growing S. coelicolor, which could have partly covered the dissolved oxygen electrode or changed the rheology of the fermentation medium due to filamentous growth ${ }^{27}$. The more accurate biomass prediction of the enhanced model reveals missing process knowledge for the description of the $\mathrm{CO}_{2}$ content in the off-gas (see Figure $3,3^{\text {rd }}$ row right, black solid line) since both, evaluation criteria (RMSE: $+14 \%$, RAD: $+18 \%$ ) and visual inspection indicate a model-data discrepancy in the exponential phase. The reason for this discrepancy is the fact that the data are obtained from off-gas measurements while the current model does not account for any transport delays in the off-gas data. Therefore, an implementation of a transport delay is advisable to improve the predictive and mechanistic quality of the model further. A functioning concept for this implementation has been shown elsewhere ${ }^{28,29}$. 
Overall, the very accurate predictions of the enhanced model and the resulting identification of missing process knowledge for dissolved oxygen and off-gas $\mathrm{CO}_{2}$ are achieved by introducing appropriate kinetics for the phosphate dynamics and subsequent re-estimation of selected parameters. Compared to the original model, most parameters remained unchanged in the enhanced model, while 11 parameters were subjected to adaptations (see Table 2).

Table 2. Overview and comparison of the most important parameters used in the original model and adjusted in the enhanced model including precipitation and polyphosphate kinetics.

\begin{tabular}{|c|c|c|c|c|c|}
\hline \multirow{3}{*}{$\begin{array}{l}\text { Parameter } \\
Y_{S X} \\
\end{array}$} & \multicolumn{2}{|c|}{ Original model $^{4}$} & \multicolumn{2}{|c|}{ Enhanced model } & \multirow{2}{*}{ Description } \\
\hline & Value & Unit & Value & Unit & \\
\hline & 0.4915 & mols/molx & 0.5100 & mols/molx & Yield coefficient \\
\hline inx & 0.2111 & $\mathrm{~mol}_{\mathrm{N}} / \mathrm{molx}$ & 0.1700 & $\mathrm{molN} / \mathrm{molx}$ & $\mathrm{N}$ content biomass composition \\
\hline ipx & 0.0094 & $\mathrm{molp} / \mathrm{molx}$ & 0.0084 & $\mathrm{molp} / \mathrm{molx}_{\mathrm{x}}$ & P content biomass composition \\
\hline $\mathrm{ms}_{\mathrm{S}}$ & 0.0410 & $1 / \mathrm{h}$ & 0.0480 & $1 / \mathrm{h}$ & Maintenance coefficient \\
\hline $\mathbf{k}_{\mathbf{D}}$ & 0.0200 & $1 / \mathrm{h}$ & 0.0150 & $1 / \mathrm{h}$ & Decay coefficient \\
\hline$t_{\text {lag }}$ & 32.9679 & $\mathrm{~h}$ & 33.15 & $\mathrm{~h}$ & Lag time \\
\hline $\mathbf{k}_{\mathbf{L}} \mathbf{a O}_{2}$ & 127.0798 & $1 / \mathrm{h}$ & 115.00 & $1 / \mathrm{h}$ & Volumetric mass transfer coefficient \\
\hline $\mathrm{K}_{\mathrm{H} 2 \mathrm{PO} 4}$ & 2.7021 & $\mathrm{mmol} / \mathrm{L}$ & 0.80 & $\mathrm{mmol} / \mathrm{L}$ & Half saturation const., growth \\
\hline $\mathbf{k}_{\mathrm{ACT}}$ & 0.0026 & $1 / \mathrm{h}$ & 0.0018 & $1 / \mathrm{h}$ & Rate constant, ACT kinetic \\
\hline $\mathrm{K}_{\text {Inhib,ACT }}$ & 0.01 & $\mathrm{mmol} / \mathrm{L}$ & 0.0050 & $\mathrm{mmol} / \mathrm{L}$ & Inhibition const., ACT kinetic \\
\hline KInhib,RED & 0.10 & $\mathrm{mmol} / \mathrm{L}$ & 0.0950 & $\mathrm{mmol} / \mathrm{L}$ & Inhibition const., RED kinetic \\
\hline $\mathbf{k}_{\mathrm{ACP}}$ & - & & 0.5 & $1 / \mathrm{h}$ & Precipitation rate constant of ACP \\
\hline $\mathbf{k}_{\text {polyP }}$ & - & & 0.003 & $1 / \mathrm{h}$ & PolyP formation rate constant \\
\hline $\mathrm{K}_{\text {total-PO4 }}$ & - & & 1.2 & $\mathrm{mmol} / \mathrm{L}$ & Half saturation const., polyP formation \\
\hline$\mu_{\max , \text { polyP }}$ & - & & $0.75^{*} \mu_{\max }$ & $1 / \mathrm{h}$ & Max. specific growth rate on polyP \\
\hline$K_{\text {polyP }}$ & - & & $2.9 * \mathrm{~K}_{\mathrm{P}}$ & $\mathrm{mmol} / \mathrm{L}$ & Half sat. const., growth on polyP \\
\hline KInhib-PO4 & - & & 0.25 & $\mathrm{mmol} / \mathrm{L}$ & Inhibition const., growth on polyP \\
\hline
\end{tabular}

These parameters were selected based upon the drawbacks identified in the original model, the impact of the implemented kinetics (ACP and polyP), their role in the process kinetics and their sensitivity, although no in-depth sensitivity analysis was carried out (which was not the scope of the paper and would require a study on its own). Some parameters needed more rigorous 
adjustment to improve the predictions, i.e. for total phosphate, total ammonia, biomass, dissolved oxygen, and ACT (parameter values highlighted in bold font). Additionally, the used parameters for the precipitation and polyphosphate kinetics are shown. For parameter adaptation a nonautomatic heuristic approach was used to learn about the impact of each parameter on the process model. Therefore, the shown values may not necessarily represent the best model performance possible compared to the results of an automatic method. However, investigating this in more detail is beyond the scope of this contribution which focuses on process kinetics for phosphate prediction. A possible method for parameter selection and identification has been proposed elsewhere $^{30}$.

\subsection{Scenario analysis (precipitation vs. polyphosphate formation)}

To reach a better understanding of the prediction of phosphorus kinetics in biotechnological processes and phosphate kinetics in fermentations with $S$. coelicolor, precipitation kinetics and polyphosphate kinetics were implemented gradually. This allowed the identification of the contribution by each phenomenon in the description of the phosphate dynamics. To illustrate the impact of precipitation and polyphosphate formation, Figure 4 includes the phosphate predictions of the original model (M0) (black dashed line), the enhanced model (M1) (black solid line), M1 with precipitation only (S1) (black dotted line) and M1 with polyP formation only (S2) (grey dash dot line). To facilitate a visual interpretation, the diagram only shows the first 75 hours fermentation time where the effects are occurring. To achieve these results, some parameters needed to be adapted for model S1 and S2 to ensure accurate prediction of the other variables. As mentioned earlier, the formation of the precipitate ACP appears to occur in the lag phase of this fermentation and allows the prediction of the total phosphate concentration (Figure 4, open circles) in the lag phase. During the exponential growth phase, the model-data discrepancy increases, 
which suggests that precipitation (S1) does not explain the phosphate dynamics over the whole fermentation time (Figure 4, black dotted line).

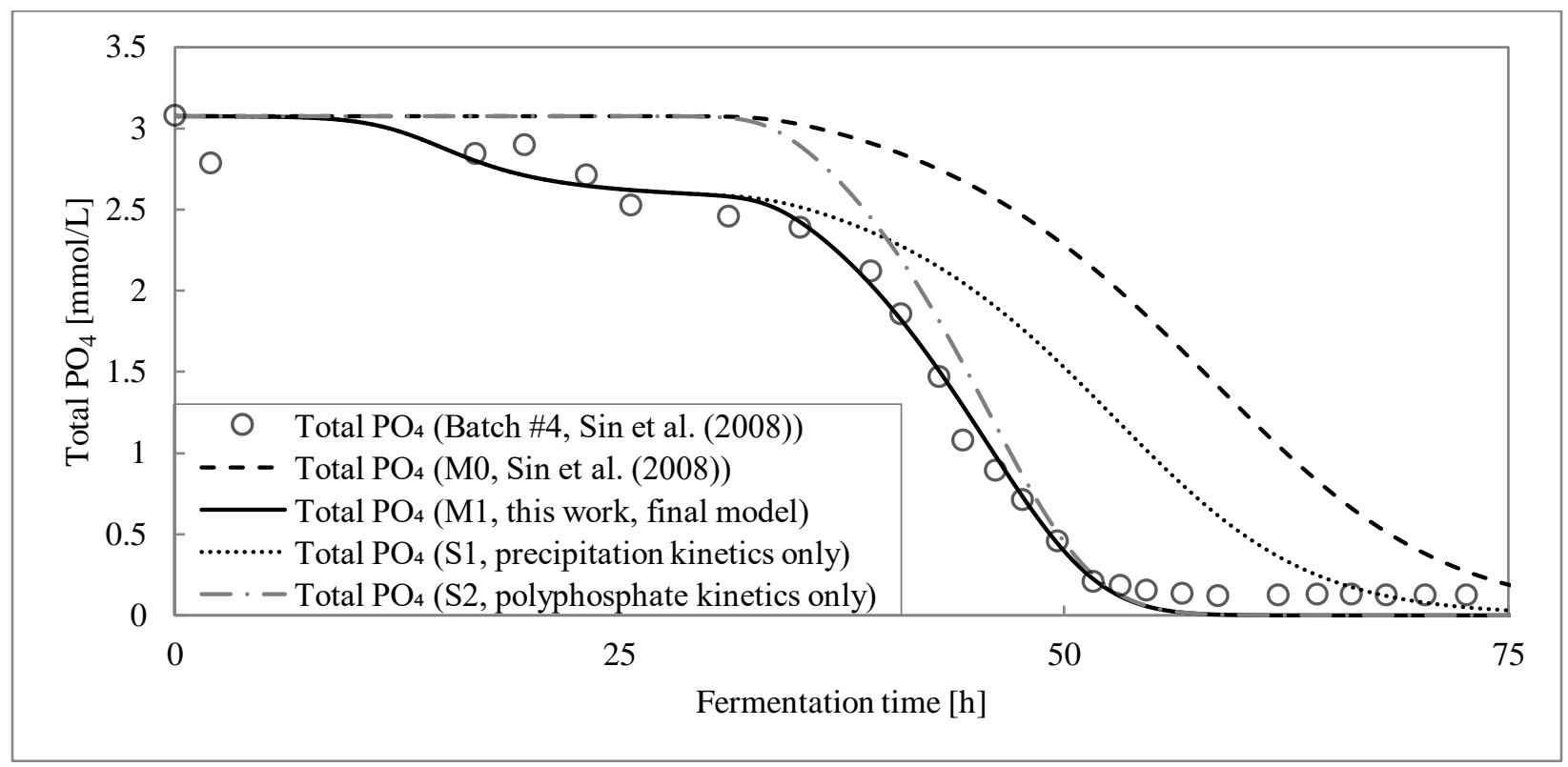

Figure 4. Evaluation of the respective impact of precipitation and polyphosphate kinetics on the prediction of phosphate dynamics. Original model (M0) by Sin et al., $2008^{4}$ (black dashed line), enhanced model (M1) (black solid line), M1 with precipitation kinetics only (S1) (black dotted line) and M1 with polyphosphate kinetics only (S2) (grey dash dot line). The experimental data points are based on batch \#4 carried out by Sin et al., 2008 (open circles).

Considering polyphosphate formation as the only occurring phenomenon on the other hand (S2) leads to a better description of the exponential phase compared to the original model, but fails to explain the phosphate dynamics in the lag phase (Figure 4, grey dash dot line). Therefore, a combined approach (M1) is required to predict the phosphate dynamics with high accuracy as we have suggested and presented in this case study (Figure 4, black solid line).

\subsection{General applicability of the proposed approach}

Even though the results presented in this study seem specific, the proposed methodology is rather general and could be applied to other biotechnological fields (wastewater treatment, anaerobic digestion). Many research groups realized the importance of precipitation and polyP kinetics when 
describing phosphorus dynamics, (particularly also due to its potential as recovered product) and the unavoidable need to consider them simultaneously ${ }^{14,31,32}$.

\section{Conclusions}

The main findings of this study are summarized in the following points:

1) A hybrid approach comprising a rigorous physico-chemical framework (speciation + precipitation) and additional biological processes (polyP formation) is proposed in this study to improve model prediction of phosphorus dynamics in biotechnological systems.

2) The approach is tested using a case study where an already published growth model of $S$. coelicolor had problems to predict phosphate dynamics. New simulations show an impressively accurate description of phosphate dynamics. The $\mathrm{RMSE}_{\leq 52 \mathrm{~h}}$ was reduced from 1.112 to $0.114(-90 \%)$ and the $\mathrm{RAD}_{\leq 52 \mathrm{~h}}$ from 1.385 to $0.052(-96 \%)$. However, since only one data-set was available, the enhanced model needs to be cross validated using additional experiments to confirm model structure and refine selected parameter values.

3) The speciation model provides an accurate description of the weak acid-base chemistry based on the composition of the fermentation media. The latter allowed identifying favorable saturation conditions (SI) to form potential multiple mineral precipitates during the lag phase. The results suggest the formation of the precipitate ACP as an explanation for the phosphate dynamics in the lag phase for this particular fermentation model. The formation of ACP needs to be confirmed by a validation experiment using an identical fermentation media composition. Based on the results the rate constant should be adapted to match the exact timing of $\mathrm{ACP}$ formation since the experimental data in the lag phase of the shown data set is not dense enough (see Figure 2). 
4) It is necessary to add the formation of polyP as potential storage product during the growth phase for an accurate description of the phosphate dynamics, since the low SI values for the identified compounds (by SI screening) do not cause any further precipitate formation. For model validation and further improvement, a validation experiment targeted at the time dependent polyP concentrations in the cells should to be carried out.

The enhanced model and the hybrid approach offer a vast number of application possibilities for different purposes (e.g. pH shift experiments, altered nutrient solution) and may be used as a starting point for the development of biotechnological systems (fermentation, wastewater treatment) where predicting the role of phosphorus compounds has a paramount importance for the correct process assessment.

\section{Software availability}

The MATLAB/SIMULINK code of the models presented in this paper is available upon request, including the implementation of the physico-chemical speciation model, the precipitation kinetics and the polyphosphate approach. Using this code, interested readers will be able to reproduce the results summarized in this study. To express interest, please contact Patrick Bürger (patrick.buerger@b-tu.de) at Brandenburg University of Technology Cottbus-Senftenberg (Germany), Prof. Krist V. Gernaey (kvg@kt.dtu.dk) or Dr. Xavier Flores-Alsina (xfa@kt.dtu.dk) at the Technical University of Denmark (Denmark). 


\author{
AUTHOR INFORMATION \\ Corresponding Author \\ *Patrick Bürger \\ Department of Particle Technology, Brandenburg University of Technology Cottbus- \\ Senftenberg, Building LG 4/3, Burger Chaussee 2, D-03046 Cottbus, Germany \\ telephone: +49 355691209 fax: +49355691121 e-mail: patrick.buerger@b-tu.de
}

\title{
Author Contributions
}

The manuscript was written through contributions of all authors with Patrick Bürger as the main author. All authors have given approval to the final version of the manuscript.

\section{Funding Sources}

Patrick Bürger gratefully acknowledges the financial support through a scholarship by the Heinrich Böll Foundation for the research stay during the project at DTU Copenhagen.

\section{Acknowledgement}

The authors greatly acknowledge Dr. Gürkan Sin, Associated Professor at the Technical University of Denmark for providing the original implementation of the $S$. coelicolor model that allowed to run this study. Patrick Bürger gratefully acknowledges the financial support through a scholarship by the Heinrich Böll Foundation. Prof. Krist V. Gernaey and Dr. Xavier FloresAlsina appreciate the financial support of the Danish Council for Independent Research under the project GREENLOGIC (7017-00175A). Dr. Flores-Alsina gratefully acknowledges the financial support of the EU- JPI project Watintech (ID 196). 


\section{Nomenclature}

\begin{tabular}{|c|c|}
\hline$a_{C a^{2+}, a_{P O_{4}}{ }^{3-}}$ & Activity of calcium ions, activity of phosphate ions \\
\hline$C_{A C P}$ & Amorphous calcium phosphate (ACP) concentration \\
\hline $\mathrm{C}_{d N \mathrm{H}_{3}}$ & Dissolved ammonia concentration \\
\hline$C_{\mathrm{dO}_{2}}$ & Dissolved oxygen concentration \\
\hline$C_{G l c}$ & Glucose concentration \\
\hline $\mathrm{C}_{\mathrm{H}_{2} \mathrm{PO}_{4}}$ & Dihydrogen phosphate concentration \\
\hline$C_{\text {polyP }}$ & Polyphosphate (polyP) concentration \\
\hline $\mathrm{C}_{\text {total }-\mathrm{PO}_{4}}$ & Total phosphate concentration (without ACP and polyP) \\
\hline$C_{X}$ & Biomass concentration \\
\hline$i_{N_{X}}$ & Nitrogen content of biomass composition \\
\hline$i_{P_{X}}$ & Phosphorus content of biomass composition \\
\hline$k_{A C P}$ & Rate constant for ACP formation \\
\hline$k_{A C T}$ & Rate constant of actinorhodin formation \\
\hline$k_{D}$ & Decay coefficient of biomass \\
\hline$k_{L} a_{O_{2}}$ & Volumetric mass transfer coefficient for oxygen \\
\hline$k_{\text {polyP }}$ & Rate constant for polyP formation \\
\hline$K_{d N H_{3}}$ & Half saturation constant of dissolved ammonia \\
\hline$K_{d O_{2}}$ & Half saturation constant of dissolved oxygen \\
\hline$K_{G l c}$ & Half saturation constant of glucose in the fermentation media \\
\hline $\mathrm{K}_{\mathrm{H}_{2} \mathrm{PO}_{4}}$ & Half saturation constant of dihydrogen phosphate \\
\hline$K_{\text {Inihib }, A C T}$ & Inhibition constant of bioavailable phosphate for ACT formation \\
\hline$K_{\text {Inihib }, \text { RED }}$ & Inhibition constant of bioavailable phosphate for RED formation \\
\hline $\mathrm{K}_{\text {Inihib-PO}}$ & Inhibition constant of external phosphate for polyP-based growth \\
\hline$K_{\text {polyP }}$ & Half saturation constant of polyphosphate \\
\hline$K_{\text {precip }, A C P}$ & Equilibrium constant for ACP precipitation \\
\hline $\mathrm{K}_{\text {total-PO}}$ & Half saturation constant of total phosphate \\
\hline$m_{S}$ & Maintenance coefficient for biomass \\
\hline$n_{A C P}$ & Reaction order of ACP formation \\
\hline$r_{A C P \text {-formation }}$ & Formation rate for amorphous calcium phosphate \\
\hline$r_{\text {polyP }}$ & Formation rate of polyphosphate \\
\hline$r_{X}$ & Biomass growth rate on external phosphate source $\left(\mathrm{H}_{2} \mathrm{PO}_{4}\right)$ \\
\hline$r_{X, p o l y P}$ & Biomass growth rate on intracellular polyphosphate \\
\hline$S I_{A C P}\left(\mathrm{Ca}_{3} \mathrm{P}_{2} \mathrm{O}_{8}\right)$ & Saturation Index of amorphous calcium phosphate \\
\hline$t$ & Fermentation time / simulation time \\
\hline$t_{\text {lag }}$ & Lag time of Streptomyces coelicolor \\
\hline$Y_{S X}$ & Yield coefficient \\
\hline$\mu_{\max }$ & Maximum specific growth rate on external phosphate source \\
\hline$\mu_{\max , p o l y P}$ & Maximum specific growth rate on intracellular polyphosphate \\
\hline
\end{tabular}




\begin{abstract}
Abbreviations
ACP, amorphous calcium phosphate; ACT, actinorhodin; AE, algebraic equation; DAE, differential algebraic equation; $\mathrm{dO}_{2}$, dissolved oxygen; $\mathrm{gCO}_{2}$, off-gas carbon dioxide content; $\mathrm{i}_{\mathrm{Nx}}$, nitrogen content in the biomass composition; $\mathrm{i}_{\mathrm{Px}}$, phosphorus content in the biomass composition; $\mathrm{k}_{\mathrm{L}} \mathrm{a}$, volumetric mass transfer coefficient of oxygen; $\mathrm{M} 0$, original model; $\mathrm{M} 1$, enhanced model; $\mathrm{NH}_{\mathrm{X}}$, total ammonia; ODE, ordinary differential equation; polyP, polyphosphate; RAD, relative average deviation; RED, undecylprodigiosin; RMSE, root mean squared error; S1, enhanced model with precipitation kinetics only; S2, enhanced model with polyphosphate kinetics only; S. coelicolor, Streptomyces coelicolor; SI, Saturation Index;
\end{abstract}

\title{
References
}

(1) Stumm, W.; Morgan, J. J. Aquatic Chemistry; 3. Edition, John Wiley \& Sons: New York, 1996.

(2) Kulaev, I.; Kulakovskaya, T. Polyphosphate and Phosphate Pump. Annu. Rev. Microbiol. 2000, 54, 709-734.

(3) Yalim Camci, İ.; Doruk, T.; Avican, Ü.; Tunca Gedik, S. Deletion of Polyphosphate Kinase Gene (ppk) has a Stimulatory Effect on Actinorhodin Production by Streptomyces coelicolor A3(2). Turk. J. Biol. 2012, 36, 373-380.

(4) Sin, G.; Ödman, P.; Petersen, N.; Eliasson Lantz, A.; Gernaey, K. V. Matrix Notation for Efficient Development of First-Principles Models Within PAT Applications: Integrated Modeling of Antibiotic Production With Streptomyces coelicolor. Biotechnol. Bioeng. 2008, 101, 153-171. 
(5) Elibol, M.; Mavituna, F. A Kinetic Model for Actinorhodin Production by Streptomyces A3(2). Process Biochem. 1999, 34, 625-631.

(6) Huang, J.; Shi, J.; Molle, V.; Sohlberg, B.; Weaver, D.; Bibb, M. J.; Karoonuthaisiri, N.; Lih, C.-J.; Kao, C. M.; Buttner, M. J; Cohen, S. N. Cross-Regulation Among Disparate Antibiotic Biosynthetic Pathways of Streptomyces coelicolor. Mol. Microbiol. 2005, 58, 1276-1287.

(7) Jankevics, A.; Merlo, M. E.; de Vries, M.; Vonk, R. J.; Takano, E.; Breitling, R. Metabolomic Analysis of a Synthetic Metabolic Switch in Streptomyces coelicolor A3(2). Proteomics 2011, 11, 4622-4631.

(8) Wentzel, A.; Sletta, H.; Stream-Consortium; Ellingsen, T. E.; Bruheim, P. Intracellular Metabolite Pool Changes in Response to Nutrient Depletion Induced Metabolic Switching in Streptomyces coelicolor. Metabolites 2012, 2, 178-194.

(9) Coze, F.; Gilard, F.; Tcherkez, G.; Virolle, M.-J.; Guyonvarch, A. Carbon-Flux Distribution within Streptomyces coelicolor Metabolism: A Comparison between the ActinorhodinProducing Strain M145 and Its Non-Producing Derivative M1146. PLoS One 2013, 8, 115.

(10) Sidebottom, A. M.; Johnson, A. R.; Karthy, J. A.; Trader, D. J.; Carlson, E. E. Integrated Metabolomics Approach Facilitates Discovery of an Unpredicted Natural Product Suite from Streptomyces coelicolor M145. ACS Chem. Biol. 2013, 8, 2008-2016. 
(11) Esnault, C.; Dulermo, T.; Smirnov, A.; Askora, A.; David, M.; Deniset-Besseau, A.;

Holand, I.-B.; Virolle, M.-J. Strong Antibiotic Production is correlated with Highly

Active Oxidative Metabolism in Streptomyces coelicolor M145. Sci. Rep. 2017, 7, 1-10.

(12) Kazadi Mbamba, C.; Batstone, D. J.; Flores-Alsina, X.; Tait, S. A Generalised Chemical Precipitation Modelling Approach in Wastewater Treatment Applied to Calcite. Water Res. 2015, 68, 342-353.

(13) Flores-Alsina, X.; Kazadi Mbamba, C.; Solon, K.; Vrecko, D.; Tait, S.; Batstone, D. J.; Jeppsson, U.; Gernaey, K. V. A Plant-Wide Aqueous Phase Chemistry Module Describing $\mathrm{pH}$ Variations and Ion Speciation/Pairing in Wastewater Treatment Process Models. Water Res. 2015, 85, 255-265.

(14) Kazadi Mbamba, C.; Flores-Alsina, X.; Batstone, D. J.; Tait, S. Validation of a Plant-Wide Modelling Approach with Minerals Precipitation in a Full-Scale WWTP. Water Res. 2016, 100, 169-183.

(15) Ödman, P. Measurement and Chemometric Modelling of Streptomyces Cultivations. Ph.D. Dissertation, Technical University of Denmark (DTU), Copenhagen, Denmark, 2010.

(16) Gernaey, K. V.; Jeppsson, U.; Vanrolleghem, P. A.; Copp, J. B. Benchmarking of Control Strategies for Wastewater Treatment Plants. IWA Scientific and Technical Report No. 23, IWA Publishing: London, UK, 2014.

(17) Lizarralde, I.; Fernández-Arévalo, T.; Brouckaert, C.; Vanrolleghem, P.; Ikumi, D. S.; Ekama, G. A.; Ayesa, E.; Grau, P. A New General Methodology for Incorporating 
Physico-Chemical Transformations into Multi-Phase Wastewater Treatment Process Models. Water Res. 2015, 74, 239-256.

(18) Vaneeckhaute, C.; Claeys, F. H. A.; Tack, F. M. G.; Meers, E.; Belia, E.; Vanrolleghem, P. A. Development, Implementation, and Validation of a Generic Nutrient Recovery Model (NRM) Library. Environ. Model. Softw. 2018, 99, 170-209.

(19) Pavlov, E.; Aschar-Sobbi, R.; Campanella, M.; Turner, R. J.; Gómez-García, M.; Abramov, Y. Inorganic Polyphosphate and Energy Metabolism in Mammalian Cells. J. Biol. Chem. 2010, 285, 9420-9428.

(20) Vagabov, V. M.; Trilisenko, L. V.; Kulaev, I. S. Dependence of Inorganic Polyphosphate Chain Length on the Orthophosphate Content in the Culture Medium of the Yeast Saccharomyces cerevisiae. Biochemistry (Moscow) 2000, 65, 349-354.

(21) Tomaschevsky, A. A.; Ryasanova, L. P.; Kulakovskaya, T. V.; Kulaev, I. S. Inorganic Polyphosphate in the Yeast Saccharomyces cerevisiae with a Mutation Disturbing the Function of Vacuolar ATPase. Biochemistry (Moscow) 2010, 75, 1052-1054.

(22) Vagabov, V. M.; Trilisenko, L. V.; Kochetkova, O. Y.; Ilchenko, A. P.; Kulaev, I. S. Effect of m-Carbonyl Cyanide 3-Chlorophenylhydrazone on Inorganic Polyphosphates Synthesis in Saccharomyces cerevisiae under Different Growth Conditions. Microbiology 2011, $80,15-20$.

(23) Kikuchi, Y.; Hijikata, N.; Yokoyama, K.; Ohtomo, R.; Handa, Y.; Kawaguchi, M.; Saito, K.; Ezawa, T. Polyphosphate Accumulation is Driven by Transcriptome Alterations that 
lead to Near-Synchronous and Near-Equivalent Uptake of Inorganic Cations in an Arbuscular Mycorrhizal Fungus. New Phytol. 2014, 204, 638-649.

(24) Doull, J. L; Vining, L. C. Nutritional Control of Actinorhodin Production by Streptomyces coelicolor A3(2): Suppressive Effects of Nitrogen and Phosphate. Appl. Microbiol. Biotechnol. 1990, 32, 449-454.

(25) Martín, J. F. Phosphate Control of the Biosynthesis of Antibiotics and Other Secondary Metabolites Is Mediated by the PhoR-PhoP System: An Unfinished Story. J. Bacteriol. 2004, 186, 5197-5201.

(26) Henze, M.; Gujer, W.; Mino, T.; van Loosdrecht, M. Activated Sludge Models ASM1, ASM2, ASM2d and ASM3; IWA Publishing: London, 2000.

(27) Olmos, E.; Mehmood, N.; Haj Husein, L.; Goergen, J. L.; Fick, M.; Delaunay, S. Effects of Bioreactor Hydrodynamics on the Physiology of Streptomyces. Bioprocess Biosyst. Eng. $\mathbf{2 0 1 3}, 36,259-272$.

(28) Wu, L.; Lange, H. C.; van Gulik, W. M.; Heijnen, J. J. Determination of in Vivo Oxygen Uptake and Carbon Dioxide Evolution Rates from Off-gas Measurements Under Highly Dynamic Conditions. Biotechnol. Bioeng. 2003, 81, 448-458.

(29) Lizarralde, I.; Fernández-Arévalo, T.; Beltrán, S.; Ayesa, E.; Grau, P. Validation of a Multi-Phase Plant-Wide Model for the Description of the Aeration Process in a WWTP. Water Res. 2018, 129, 305-318. 
(30) López, C.; Diana, C.; Barz, T.; Peñuela, M.; Villegas, A.; Ochoa, S.; Wozny, G. ModelBased Identifiable Parameter Determination Applied to a Simultaneous Saccharification and Fermentation Process Model for Bio-Ethanol Production. Biotechnol. Prog. 2013, 29, 1064-1082.

(31) Wang, R.; Li, Y.; Chen, W.; Zou, J.; Chen, Y. Phosphate Release Involving PAOs Activity During Anaerobic Fermentation of EBPR Sludge and the Extension of ADM1. Chem. Eng. J. 2016, 287, 436-447.

(32) Fernández-Arévalo, T.; Lizarralde, I.; Fdz-Polanco, F.; Pérez-Elvira, S. I.; Garrido, J. M.; Puig, S.; Poch, M.; Grau, P.; Ayesa, E. Quantitative Assessment of Energy and Resource Recovery in Wastewater Treatment Plants based on Plant-Wide Simulations. Water Res. $\mathbf{2 0 1 7}, 118,272-288$ 


\section{For Table of Contents Only}

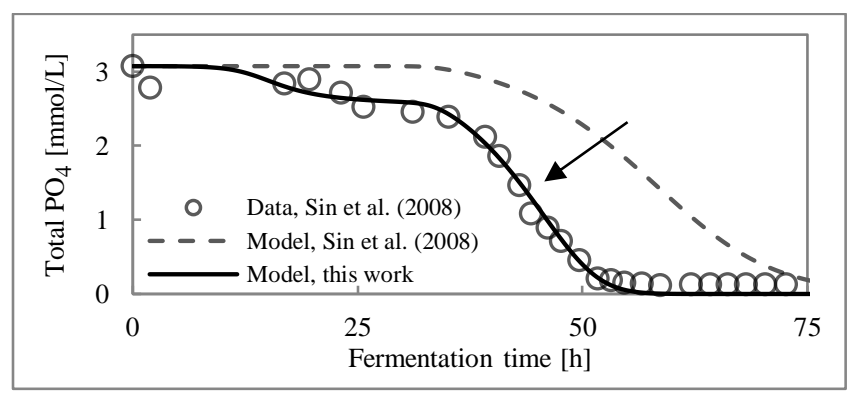

